\title{
Identification of Risk Factors for Nephrotoxicity in Patients Receiving Extended-Duration, High-Trough Vancomycin Therapy
}

\author{
Claire Contreiras, Michael Legal, Tim T Y Lau, Rosanne Thalakada, Stephen Shalansky, and Mary H H Ensom
}

\begin{abstract}
Background: In the past, impurities in vancomycin formulations were thought to contribute to nephrotoxicity. In contrast, when current, purer formulations are dosed at conventional trough levels (i.e., $5-15 \mathrm{mg} / \mathrm{L}$ ), the incidence of nephrotoxicity is relatively low. Recent guidelines have recommended targeting higher vancomycin trough levels in treatment of complicated methicillin-resistant Staphylococcus aureus infections. Dosing based on these higher trough levels may be associated with nephrotoxicity, so the potential risk factors for vancomycin-associated nephrotoxicity require clearer definition.
\end{abstract}

Objectives: To determine the occurrence of nephrotoxicity in patients receiving more than 7 days of vancomycin therapy with high trough levels $(15-20 \mathrm{mg} / \mathrm{L})$ and to identify and evaluate specific risk factors related to development of vancomycin-associated nephrotoxicity (i.e., serum creatinine $\geq 44.2 \mu \mathrm{mol} / \mathrm{L}$ or increase $\geq 50 \%$ [i.e., $\geq 26.2 \mu \mathrm{mol} / \mathrm{L}$ ] from baseline on 2 consecutive days).

Methods: Health care records were reviewed for patients seen at 2 major teaching hospitals between January 2008 and March 2011. Patients who had attained high trough levels of vancomycin were screened for eligibility. Patients with unstable renal function, those undergoing hemodialysis, and those for whom dosage and/or sampling times were unclear were excluded. Univariate and multivariate analyses were performed to identify risk factors associated with nephrotoxicity. Univariate variables with $p<0.1$ were included in the logistic regression model.

Results: Of the 176 patients with high trough levels included in the analysis, 24 (14\%) experienced nephrotoxicity. In univariate analysis, admission to a general medicine unit (the setting of care for 16 [67\%] of the 24 patients with nephrotoxicity) and extended duration of vancomycin treatment were identified as risk factors for nephrotoxicity $(p<0.1)$. Other risk factors included gastrointestinal comorbidity ( $p=0.056)$, malignancy $(p=0.044)$, and febrile neutropenia $(p=0.032)$. Multivariate analysis identified treatment on general medicine units and treatment courses longer than 7 days as independent predictors of vancomycin-associated nephrotoxicity.

Conclusion: Patients being treated on general medicine units and those receiving vancomycin for more than 7 days had an increased likelihood of experiencing nephrotoxicity. The increased risk for patients on general medicine units is likely multifactorial. The relationship between treatment duration and risk of nephrotoxicity appeared to be linear. When

\section{RÉSUMÉ}

Contexte : On croyait autrefois que les impuretés contenues dans les préparations de vancomycine pouvaient contribuer à causer une néphrotoxicité. D’un autre côté, lorsque les préparations actuelles plus pures sont dosées selon les concentrations minimales classiques (c.-à-d., $5-15 \mathrm{mg} / \mathrm{L}$ ), les cas de néphrotoxicité sont relativement peu nombreux. Des lignes directrices récentes recommandaient de viser des concentrations minimales plus élevées de vancomycine pour traiter les infections compliquées à Staphylococcus aureus résistant à la méthicilline. Comme ces concentrations minimales plus élevées peuvent être associées à la néphrotoxicité, il est nécessaire de mieux définir les facteurs de risque potentiels de néphrotoxicité associée à l'administration de vancomycine.

Objectifs : Déterminer le nombre de cas de néphrotoxicité chez les patients recevant un traitement de vancomycine de plus de sept jours avec des concentrations minimales élevées $(15-20 \mathrm{mg} / \mathrm{L}$ ), ainsi que cerner et évaluer les facteurs de risque précis associés à une néphrotoxicité causée par la vancomycine (c.-à-d., une créatinine sérique de $\geq 44,2$ $\mu \mathrm{mol} / \mathrm{L}$ ou une augmentation de $\geq 50 \%$ [c.-à-d., $\geq 26,2 \mu \mathrm{mol} / \mathrm{L}]$ par rapport aux valeurs de base pendant deux jours consécutifs).

Méthodes : Les dossiers médicaux des patients rencontrés entre janvier 2008 et mars 2011 dans deux importants hôpitaux universitaires ont été examinés. Les patients chez qui les concentrations minimales de vancomycine avaient atteint des valeurs élevées ont été évalués afin de juger s'ils étaient admissibles. Les patients dont la fonction rénale était instable, ceux qui subissaient une hémodialyse et ceux pour qui la posologie ou le temps d'échantillonnage n'étaient pas clairs ont été exclus. Des analyses univariée et multivariée ont été effectuées pour cerner les facteurs de risque associés à une néphrotoxicité. Les variables univariées dont le $p$ était inférieur à 0,1 ont été incorporées dans le modèle de régression logistique.

Résultats : Parmi les 176 patients avec des concentrations minimales élevées, 24 (14\%) ont souffert de néphrotoxicité. Lors de l'analyse univariée, l'hospitalisation dans un service de médecine générale (unité où les soins étaient prodigués pour 16 [67\%] des 24 patients souffrant de néphrotoxicité) ainsi que la prolongation du traitement avec la vancomycine ont été reconnues comme des facteurs de risque de néphrotoxicité $(p<0,1)$. La comorbidité gastro-intestinale $(p=0,056)$, le cancer $(p=0,044)$ et la neutropénie fébrile $(p=0,032)$ représentaient aussi des facteurs de risque. L'analyse multivariée a déterminé que le traitement dans un service de médecine générale et les traitements de plus de sept jours étaient des indicateurs indépendants de risque de néphrotoxicité associée à la prise de vancomycine. 
using extended-duration, high-trough vancomycin therapy, clinicians should be vigilant in monitoring for nephrotoxicity.

Keywords: vancomycin, nephrotoxicity, high-trough therapy

Can J Hosp Pharm. 2014;67(2):126-32
Conclusion : Les patients ayant été traités dans un service de médecine générale et ceux ayant reçu un traitement de vancomycine de plus de sept jours présentaient un plus grand risque de néphrotoxicité. Le risque accru pour les patients séjournant dans un service de médecine générale est probablement multifactoriel. Le lien entre la durée du traitement et le risque de néphrotoxicité semble linéaire. Lorsqu'ils font appel à un traitement de vancomycine à concentration minimale élevée, les cliniciens doivent procéder à un suivi attentif pour déceler tout signe de néphrotoxicité.

Mots clés : vancomycine, néphrotoxicité, traitement à concentration minimale élevée

[Traduction par l'éditeur]

\section{INTRODUCTION}

$\mathrm{V}$ ancomycin is a glycopeptide antibiotic that remains a mainstay of treatment for infections caused by methicillinresistant strains of Staphylococcus aureus (MRSA). ${ }^{1}$ Early use of vancomycin (i.e., when the drug first became available) was associated with a number of adverse effects, including nephrotoxicity. However, further investigation revealed that these effects were likely due to impurities in the product rather than to the drug itself. ${ }^{1-3}$ The manufacturing process has improved over time, and the incidence of nephrotoxicity is low when vancomycin is used at conventional trough levels (i.e., $5-15 \mathrm{mg} / \mathrm{L}$ ) and not in combination with known nephrotoxins. ${ }^{1,3,4}$

Recent guidelines have suggested that higher vancomycin trough levels $(15-20 \mathrm{mg} / \mathrm{L})$ are needed in the treatment of complicated MRSA infections (such as bacteremia, endocarditis, osteomyelitis, meningitis, and hospital-acquired pneumonia). ${ }^{1}$ The trough level is a surrogate marker for the ratio of area under the curve to minimum inhibitory concentration (AUC/MIC). A target AUC/MIC of 400 or above appears to be associated with optimal clinical and bacterial response to vancomycin. ${ }^{1}$ A trough level of $15-20 \mathrm{mg} / \mathrm{L}$ is expected to achieve this AUC/MIC for organisms with MIC of $1 \mathrm{mg} / \mathrm{L}$ or below. ${ }^{1}$ Given that higher trough levels are becoming more frequent in clinical practice, the potential risk factors for vancomycin-associated nephrotoxicity need to be more clearly defined. Nephrotoxicity has both short- and long-term implications. ${ }^{5}$ Even when the acute changes in kidney function resolve, patients may be left with permanent kidney damage, which may in turn place them at increased risk of long-term adverse events. ${ }^{5}$ The mechanism by which vancomycin causes nephrotoxicity is not completely understood; however, animal studies have suggested that oxidative stress in the proximal and medullary regions is the cause of vancomycin-associated renal injury. ${ }^{1}$
Several retrospective studies and one prospective study have investigated how vancomycin trough levels, duration of therapy, and/or concomitant administration of nephrotoxins affect the occurrence of nephrotoxicity. ${ }^{6-13}$ In all but one of these studies, the occurrence of nephrotoxicity increased in association with increasing trough levels. ${ }^{6,8-13}$ Pritchard and others, ${ }^{6}$ through analysis of receiver operating characteristic (ROC) curves, determined that a trough level of $14 \mathrm{mg} / \mathrm{L}$ was the threshold for development of nephrotoxicity.

Numerous researchers have investigated whether the duration of treatment affects the development of nephrotoxicity. ${ }^{6,7,11,14}$ In only one of these studies did prolonged therapy increase the risk of nephrotoxicity. ${ }^{7}$ Pritchard and others, ${ }^{6}$ again using ROC curve analysis, determined that the threshold duration was 7 days.

The concomitant use of vancomycin with other nephrotoxins has been reported in some studies. ${ }^{4,6,8,11,15,16}$ In a 2008 study, Lodise and others ${ }^{4}$ reported insufficient evidence to associate concomitant nephrotoxins with development of nephrotoxicity; in another study, published in 2009, the same authors reported no association. ${ }^{8}$ Three studies showed that the concurrent use of nephrotoxins significantly increased the risk of nephrotoxicity; however, none of these specified the number of nephrotoxins or the duration of exposure. ${ }^{11,15,16}$ One study was unable to detect the effect of concomitant nephrotoxins and comorbid disease states on the development of nephrotoxicity, but this was likely due to the small sample size. ${ }^{6}$

Although the literature suggests that higher trough levels of vancomycin and longer duration of therapy increase the risk of nephrotoxicity, the extent to which various factors contribute to this adverse effect is as yet unclear. The primary objective of the research reported here was to more effectively (as compared with previous publications) characterize the factors (including demographic characteristics, comorbid diseases, and concomitant nephrotoxins) that increase the risk of vancomycin- 
associated nephrotoxicity in patients receiving high-trough vancomycin treatment for more than 7 days. The secondary objectives were to define the occurrence of nephrotoxicity in this population at local hospitals and to describe the time course and clinical outcome of nephrotoxicity.

\section{METHODS}

A retrospective analysis of health care records was conducted at Vancouver General Hospital (a 950-bed tertiary care centre) and St Paul's Hospital (a 440-bed tertiary care centre) in Vancouver, British Columbia. Potential participants were identified by searching pharmacy databases that listed patients in whom a high vancomycin trough level (15-20 $\mathrm{mg} / \mathrm{L}$ ) had been achieved between January 2008 and March 2011. Approval for the study was granted by the University of British Columbia - Providence Health Care Research Ethics Board and by the Vancouver Coastal Health and Providence Health Care research institutes.

Patients were included in the study if they were 19 years of age or older, had received IV vancomycin therapy for more than 7 days, had one serum creatinine measurement before initiation of vancomycin or within the first week of treatment, had achieved at least one steady-state vancomycin trough level (i.e., sample collected after administration of at least 3 doses) of 15-20 mg/L, and had stable serum creatinine during the first 7 days of therapy (i.e. no more than a $25 \%$ change in serum creatinine on 2 consecutive days). Patients with renal failure (creatinine clearance $<10 \mathrm{~mL} / \mathrm{min}$ ), those undergoing hemodialysis, and those for whom dosage and/or sampling times were unclear or undocumented were excluded. Hypothesized predictors for the development of nephrotoxicity were defined before data collection (see Appendix 1; available online at www.cjhp-online.ca/index.php/cjhp/issue/view/101/showToc).

For included patients, the following data were collected from the chart and other health care records (e.g., laboratory data): age, sex, weight, admission diagnosis, admission and discharge dates, clinical area of care, serum creatinine levels, vancomycin levels, medication regimens, start and stop dates for each medication, concurrent nephrotoxins (as defined in Appendix 1), comorbid disease states, type of infection, nephrology consultations, and presence of urine or serum eosinophilia. To be considered in the analysis of risk factors, any concurrent nephrotoxic medications must have been initiated a minimum of 1 day before the first rise in serum creatinine or stopped not more than 1 day before the first rise in serum creatinine. Two definitions of nephrotoxicity were used. The first definition was based on an increase in serum creatinine $\geq 44.2 \mu \mathrm{mol} / \mathrm{L}$ or an increase in serum creatinine $\geq 50 \%$ from baseline on 2 consecutive days. This definition reflects the definition of nephrotoxicity used by the majority of previous studies pertaining to high-trough vancomycin treatment. The second definition employed in this study was based on an increase in serum creatinine $\geq 26.2 \mu \mathrm{mol} / \mathrm{L}$ from baseline on 2 consecutive days. This definition was proposed by the Acute Kidney Injury Network to help identify drug-induced kidney damage earlier, in the hopes of improving outcomes. ${ }^{7}$ For patients with nephrotoxicity, the RIFLE criteria were used to describe the extent of acute kidney injury, where the RIFLE definitions are as follows: Risk $=1.5$ times increase in serum creatinine (SCr) or $25 \%$ reduction in glomerular filtration rate (GFR); Injury $=2$ times increase in SCr or $50 \%$ reduction in GFR; Failure $=3$ times increase in SCr, $75 \%$ reduction in GFR, or $\mathrm{SCr}>354 \mu \mathrm{mol} / \mathrm{L}$; Loss $=$ sustained acute kidney injury $>4$ weeks; and End stage kidney disease = sustained acute kidney injury $>3$ months. ${ }^{17}$

\section{Statistical Analysis}

Univariate analysis was used to compare patients who experienced nephrotoxicity with those who did not in relation to the hypothesized risk factors. Dichotomous variables were analyzed with the $\chi^{2}$ test and continuous variables with the $t$ test for independent samples. Results from the univariate analysis were used to identify variables for a multivariate model. For inclusion in the logistic regression model, the threshold $p$ value was 0.1 . Logistic regression was used to identify independent predictors of vancomycin-associated nephrotoxicity. SPSS version 20 statistical software (IBM, Armonk, New York) was used and a backward conditional method employed. Possible predictors were identified, and each model comprised only 4 variables to maintain model stability. The a priori $p$ value for statistical significance was 0.05 , and the Hosmer-Lemeshow goodness-of-fit statistic was employed to evaluate how well the model described the observed data. Descriptive statistics were used to report the results for the secondary objectives.

\section{RESULTS}

In total, 348 patients were identified in the pharmacy databases as having achieved high vancomycin trough levels. Of these, 176 met the inclusion criteria. For the majority of those excluded, the duration of vancomycin therapy was too short (i.e., 7 days or less). Among the 176 included patients, the mean age was 57.8 years, and about two-thirds were men (Table 1). The mean serum creatinine level at baseline was $100.8 \mu \mathrm{mol} / \mathrm{L}$. Patients received a median of 3 weeks of vancomycin treatment, with a median daily dose of $2 \mathrm{~g}$. The majority of patients were on either a medical or a surgical unit. The most common infection being treated was osteomyelitis or septic arthritis, and the most common causative organism was MRSA.

Nephrotoxicity occurred in 24 (14\%) of the 176 patients; the mean peak serum creatinine recorded in these patients was 
Table 1. Demographic Characteristics of Patients

\begin{tabular}{|c|c|}
\hline Characteristic & $\begin{array}{c}\text { Value for Study } \\
\text { Population }(n=176)\end{array}$ \\
\hline Sex, no. (\%) male & $119(68)$ \\
\hline Age (years), mean \pm SD & $57.8 \pm 17.7$ \\
\hline Weight $(\mathrm{kg})$, mean $\pm \mathrm{SD}$ & $73.1 \pm 17.1$ \\
\hline Vancomycin dose (mg/day), median (IQR) & $2000(1500-2500)$ \\
\hline Baseline $\mathrm{SCr}(\mu \mathrm{mol} / \mathrm{L})$, mean $\pm \mathrm{SD}$ & $84.6 \pm 38.6$ \\
\hline Baseline $\mathrm{CrCl}(\mathrm{mL} / \mathrm{min})$, mean $\pm \mathrm{SD}$ & $100.8 \pm 48.8$ \\
\hline Length of stay (days), median (IQR) & $26(17-48)$ \\
\hline Length of treatment (days), median (IQR) & $15(11-23)$ \\
\hline Length of treatment (weeks), median (IQR) & $3(2-4)$ \\
\hline Clinical area medicine, no. (\%) of patients & $84(48)$ \\
\hline Concurrent receipt of nephrotoxins, ${ }^{*}$ no. (\%) of patients & $113(64)$ \\
\hline Experienced nephrotoxicity, no. (\%) & $24(14)$ \\
\hline
\end{tabular}

\section{Table 2. Clinical Course of Nephrotoxicity}

\begin{tabular}{lc} 
Variable & Value \\
\hline Peak SCr $(\mu \mathrm{mol} / \mathrm{L})$, mean \pm SD & $134.5 \pm 53.4$ \\
Time to first rise in SCr from start of therapy (days), median (IQR) & $14(10-21)$ \\
Time to peak SCr from start of therapy (days), median (IQR) & $15(12-23)$ \\
Time to resolution from peak SCr (days), median (IQR) & $7(4-9)$ \\
RIFLE category, no. (\%) of patients* & $17(70.8)$ \\
$\quad$ Risk & $3(12.5)$ \\
$\quad$ Injury & $1(4.2)$ \\
$\quad$ Failure & $3(2.5)$ \\
SCr increase $\geq 26.4 \mu m o l / L$, no. (\%) of patients & \\
IQR = interquartile range, SCr = serum creatinine, SD = standard deviation. \\
*Among patients with nephrotoxicity.
\end{tabular}

$135 \mu \mathrm{mol} / \mathrm{L}$. Serum creatinine first rose above the nephrotoxicity threshold after a median of 14 days of treatment and peaked after 15 days of treatment. According to the RIFLE criteria for describing the extent of nephrotoxicity in these 24 patients, 17 (71\%) were in the "risk" category, 3 (12\%) were in the "injury" category, and 1 (4\%) was in the "failure" category. The remaining 3 patients met the second definition of nephrotoxicity as described by the Acute Kidney Injury Network. ${ }^{7}$ Patients who experienced nephrotoxicity had a longer median length of stay than those who did not (43 days versus 25 days).

In 13 of the patients, the nephrotoxicity did not resolve before discharge; however, serum creatinine levels appeared to have peaked and were trending downward by the time of discharge in all of these cases. For the 11 patients whose nephrotoxicity resolved before discharge, resolution took a median of 7 days from the date of peak serum creatinine (Table 2 ). According to chart progress notes, vancomycin was implicated in only 4 of the 24 cases, and in these 4 cases, the medication was discontinued. In 7 patients, the vancomycin dose was adjusted. The adjustments were based on supratherapeutic vancomycin trough concentrations (23-40.7 mg/L); however, each patient also had elevated serum creatinine. The nephrology service was consulted in 3 cases, but none of the 24 patients required hemodialysis.

Univariate analysis revealed that patients who experienced nephrotoxicity were more likely to be on a general medicine unit $(p=0.046)$ or to have received a longer duration of vancomycin therapy expressed in weeks $(p=0.080)$ (Table 3$)$. Patients with nephrotoxicity were also more likely to have gastrointestinal comorbidity $(p=0.056)$ or malignancy $(p=0.044)$ or to be receiving treatment for febrile neutropenia $(p=0.032)$. In the univariate analysis, these variables had $p$ values less than 0.1 ; however, they accounted for very small numbers of patients with the event of interest. Patients who did not experience nephrotoxicity were more likely to be taking an angiotensin-converting enzyme (ACE) inhibitor or an angiotensin receptor blocker (ARB) $(p=0.029)$, to have received contrast dye $(p=0.054)$, to be undergoing treatment for sepsis 


\section{Table 3. Univariate Analysis for Nephrotoxicity}

\begin{tabular}{|c|c|c|c|}
\hline \multirow[b]{2}{*}{ Variable } & \multicolumn{2}{|c|}{ Nephrotoxicity } & \multirow[b]{2}{*}{$p$ value } \\
\hline & Yes $(n=24)$ & No $(n=152)$ & \\
\hline Age (years), mean \pm SD & $60 \pm 19$ & $57 \pm 17$ & 0.43 \\
\hline Weight (kg), mean \pm SD & $74.5 \pm 17.6$ & $72.9 \pm 17.1$ & 0.68 \\
\hline Baseline $\mathrm{CrCl}(\mathrm{mL} / \mathrm{min})$, mean $\pm \mathrm{SD}$ & $103.3 \pm 49$ & $100.4 \pm 48.9$ & 0.79 \\
\hline Baseline SCr* $(\mu \mathrm{mol} / \mathrm{L})$, mean $\pm \mathrm{SD}$ & $84.6 \pm 43.1$ & $84.5 \pm 38$ & $>0.99$ \\
\hline \multicolumn{4}{|l|}{ Duration of vancomycin treatment, mean \pm SD } \\
\hline In days & \multirow{2}{*}{$\begin{array}{c}24.8 \pm 16.1 \\
3.8 \pm 2.2\end{array}$} & \multirow{2}{*}{$\begin{array}{c}17.5 \pm 10.3 \\
2.9 \pm 1.3\end{array}$} & 0.044 \\
\hline In weeks* & & & 0.080 \\
\hline \multicolumn{4}{|l|}{ Clinical area, no. (\%) of patients } \\
\hline Medicine* & $16(67)$ & $68 \quad(45)$ & 0.046 \\
\hline ICU & $2 \quad(8)$ & 14 & 0.90 \\
\hline \multicolumn{4}{|l|}{ Type of infection treated, no. (\%) of patients } \\
\hline Osteomyelitis or septic arthritis & $5 \quad(21)$ & $32 \quad(21)$ & 0.90 \\
\hline Pneumonia & $5 \quad(21)$ & $19 \quad(12)$ & 0.31 \\
\hline Febrile neutropeniat & $2 \quad(8)$ & $2 \quad(1)$ & 0.032 \\
\hline \multicolumn{4}{|l|}{ Organisms identified, no. (\%) of patients } \\
\hline MRSA & $12(48)$ & $78 \quad(51)$ & 0.76 \\
\hline MSSA† & $2 \quad(8)$ & $2 \quad(1)$ & 0.032 \\
\hline Enterococcus & $3(12)$ & (7) & 0.34 \\
\hline \multicolumn{4}{|l|}{ Comorbidity, no. (\%) of patients } \\
\hline Diabetes mellitus & $6 \quad(25)$ & $30 \quad(20)$ & 0.62 \\
\hline Hypertension & $9 \quad(38)$ & $49 \quad(32)$ & 0.71 \\
\hline Gastrointestinal comorbidity & $6 \quad(25)$ & $16 \quad(11)$ & 0.056 \\
\hline Malignancy & $6 \quad(25)$ & $15 \quad(10)$ & 0.044 \\
\hline HIV infection & (0) & $20 \quad(13)$ & 0.059 \\
\hline Sepsis & $(0)$ & $20 \quad(13)$ & 0.059 \\
\hline \multicolumn{4}{|l|}{ Concurrent nephrotoxin, no. (\%) of patients } \\
\hline Any & 11 (46) & $102 \quad(67)$ & 0.043 \\
\hline ACE inhibitor or ARB* & $(4)$ & $36 \quad(24)$ & 0.029 \\
\hline IV contrast dye $\dagger$ & (8) & $40 \quad(26)$ & 0.054 \\
\hline NSAID & (4) & $25 \quad(16)$ & 0.10 \\
\hline
\end{tabular}

$\mathrm{ACE}=$ angiotensin-converting enzyme, $\mathrm{ARB}=$ angiotensin receptor blocker, $\mathrm{CrCl}=$ creatinine clearance, $\mathrm{ICU}=$ intensive care unit, MRSA = methicillin-resistant Staphylococcus aureus, MSSA = methicillin-sensitive Staphylococcus aureus, NSAID = nonsteroidal anti-inflammatory drug, $\mathrm{SCr}=$ serum creatinine, SD = standard deviation.

* Variables included in multivariate logistic regression.

†Excluded from multivariate logistic regression (even though $p<0.1$ ) because of the small number of patients affected.

( $p=0.059)$, or to be HIV-positive $(p=0.059)$. These differences were all statistically significant in the univariate analysis.

Being a patient on a general medicine unit and duration of vancomycin treatment (measured in weeks) were both independent predictors of vancomycin-associated nephrotoxicity after controlling for baseline serum creatinine and concurrent use of ACE inhibitor or ARB (Table 4). The $p$ value for the Hosmer-Lemeshow goodness-of-fit statistic for the regression model was 0.81 , which indicated a good association between the predicted probability of vancomycin-associated nephrotoxicity and observed cases of vancomycin-associated nephrotoxicity. An independent $t$ test was used to compare serum creatinine at baseline between patients on general medicine units and patients on other units. Patients on general medicine units actually had lower serum creatinine at baseline $(81 \pm 40 \mu \mathrm{mol} / \mathrm{L}$ versus $87 \pm 37 \mu \mathrm{mol} / \mathrm{L}$ ); however, this difference was not statis- tically significant. In an exploratory model using duration of treatment expressed in days instead of weeks, the duration of treatment was also identified as an independent predictor of vancomycin-associated nephrotoxicity (odds ratio [OR] 1.05, $95 \%$ confidence interval [CI] 1.01-1.08; $p=0.01$ ).

The proportion of patients receiving concurrent nonsteroidal anti-inflammatory drugs (NSAIDs) was $4 \%(1 / 25$ patients) among those with nephrotoxicity and 16\% (25/152 patients) among those without nephrotoxicity. Unfortunately, there were insufficient numbers for further analysis. When data for patients who were taking any concurrent nephrotoxins were entered into a multivariate model with the other evaluated variables, the results showed that these patients were less likely to experience nephrotoxicity than those not taking a nephrotoxin, but this result was not statistically significant (OR 0.46 , $95 \%$ CI $0.19-1.13 ; p=0.09$ ). 
This single copy is for your personal, non-commercial use only.

For permission to reprint multiple copies or to order presentation-ready copies for distribution, contact CJHP at cjhpedit@cshp.ca

\section{Table 4. Predictors of Vancomycin-Associated Nephrotoxicity by Multivariate Analysis*}

\begin{tabular}{|c|c|c|}
\hline Parameter & Adjusted OR (95\% Cl) & $p$ value \\
\hline Clinical area general medicine & $2.57 \quad(1.01-6.58)$ & 0.048 \\
\hline Duration of vancomycin treatment (weeks) & $1.35(1.04-1.76)$ & 0.025 \\
\hline Concurrent use of $A C E$ inhibitor or $A R B$ & $0.13 \quad(0.02-1.00)$ & 0.049 \\
\hline
\end{tabular}

\section{DISCUSSION}

Previous literature defined a vancomycin trough level of 14 $\mathrm{mg} / \mathrm{L}$ and duration of treatment of 7 days as the minimum thresholds for development of nephrotoxicity. ${ }^{6}$ In the study reported here, data were evaluated for patients with a trough level of $15-20 \mathrm{mg} / \mathrm{L}$ and more than 7 days of treatment for the following practical reasons: (1) common practice at the 2 study hospitals was to target trough levels of $15-20 \mathrm{mg} / \mathrm{L}$ for invasive infections, as per consensus guidelines, ${ }^{1}$ and for applicability to practice, we believed it was important to mirror these trough levels; (2) duration of $>7$ days (rather than $\geq 7$ days) was selected because Vancouver General Hospital uses an automatic stop date for vancomycin of 7 days unless a specific duration of therapy is defined at the time of prescribing; and (3) we wanted to focus the analysis on patients who were truly receiving "extended therapy", excluding those who received a standard duration of therapy, as defined by the automated default setting of 7 days.

The $14 \%$ incidence of nephrotoxicity observed in this study of patients who received extended-duration, high-trough vancomycin therapy was consistent with certain other studies, which have reported rates of $12.6 \%$ and $17 \% .^{11,12}$ In one prospective study, ${ }^{13}$ the incidence of nephrotoxicity was $29.6 \%$. Although it is unclear why the incidence was higher in that study, it may be that more of the patients had supratherapeutic levels. In the study reported here, despite the increased rate of nephrotoxicity when higher trough levels were targeted (relative to conventional trough levels), the nephrotoxicity that occurred was reversible and not severe.

Identification of the clinical area of general medicine as an independent predictor of vancomycin-associated nephrotoxicity, regardless of therapy duration, is difficult to explain but is likely multifactorial. That is, patients on a general medicine unit may be inherently more severely ill than those on, for example, a general surgery unit. Unfortunately, no accurate measure was available to determine the acuity of illness. Serum creatinine at baseline was assessed in the general medicine patients as a potential surrogate marker of "severity of illness". However, these patients actually had lower baseline serum creatinine than those on other units. Other possible reasons for this observation are that patients on general medicine units may not be monitored as closely as patients on other units or may be more likely to have comorbidities that put them at increased risk of nephrotoxicity. This finding may warrant further investigation into differences in how these patients are managed.

Duration of treatment was a consistent predictor of nephrotoxicity even when expressed in different units (i.e., days versus weeks). The consistency of this finding, despite the use of different measures, indicates the stability of the multivariate model. The OR values calculated for days and weeks also point to the model's stability. A patient's risk of vancomycin-associated nephrotoxicity increased by a factor of 1.05 for each additional day of therapy beyond 7 days and by a factor of 1.35 for each additional week of therapy. The relationship between duration of treatment and development of vancomycin-associated nephrotoxicity appeared to follow a linear trend. From this finding, it appears that a patient's risk of vancomycin-associated nephrotoxicity may continue to increase as duration of vancomycin therapy increases.

Other previously reported risk factors for vancomycinassociated nephrotoxicity include increased body weight and intensive care unit stay. ${ }^{4,8,12}$ The sample size in the current study was inadequate to analyze these factors.

Further investigation into whether concurrent use of NSAIDs was an independent predictor of nephrotoxicity was also of interest. Anecdotally, practitioners at both sites had noted abrupt increases in serum creatinine among patients taking both vancomycin and NSAIDs. Unfortunately, the sample size in this study was insufficient to offer further insights on this issue. Several previous studies showed that concurrent use of any known nephrotoxin was a predictor of vancomycin-associated nephrotoxicity. ${ }^{11,15,16}$ However, in the study reported here, concurrent use of nephrotoxins was not identified as an independent predictor of vancomycinassociated nephrotoxicity. Although this result was surprising, it may be explained by the increased monitoring of patients who were receiving known nephrotoxins along with vancomycin. It is also likely that the use of other nephrotoxins was avoided among patients receiving vancomycin who already had tenuous renal function.

The limitations of the study included its observational and retrospective nature. The results did not reveal a causal 
relationship between more than 7 days of high-trough vancomycin treatment and nephrotoxicity. However, a larger sample size might have allowed for a more robust correlation and identification of additional variables related to increased incidence of vancomycin-associated nephrotoxicity. It may be beneficial to validate the current multivariate model by evaluating and testing its predictive performance in a separate cohort of patients.

\section{CONCLUSION}

Patients being treated on a general medicine unit and receiving vancomycin courses longer than 7 days appeared to have an increased likelihood of experiencing nephrotoxicity. The increased risk among patients on the general medicine unit was likely multifactorial. These results suggest that the relationship between duration of treatment and risk of nephrotoxicity follows a linear trend. When using extended-duration, hightrough vancomycin therapy, clinicians should be vigilant in monitoring for nephrotoxicity.

\section{References}

1. Rybak M, Lomaestro B, Rotschafer JC, Moellering R Jr, Craig W, Billeter $\mathrm{M}$, et al. Therapeutic monitoring of vancomycin in adult patients: a consensus review of the American Society of Health-System Pharmacists, the Infectious Diseases Society of America, and the Society of Infectious Diseases Pharmacists. Am J Health Syst Pharm. 2009;66(1):82-98. Erratum in: Am J Health Syst Pharm. 2009;66(10):887.

2. Hazlewood KA, Brouse SD, Pitcher WD, Hall RG. Vancomycin-associated nephrotoxicity: grave concern or death by character assassination? $A m \mathrm{~J}$ Med. 2010;123(2):182.e1-7.

3. Rybak MJ, Albrecht LM, Boike SC, Chandrasekar PH. Nephrotoxicity of vancomycin, alone and with an aminoglycoside. J Antimicrob Chemother. 1990;25(4):679-87.

4. Lodise TP, Lomaestro B, Graves J, Drusano GL. Larger vancomycin doses (at least four grams per day) are associated with an increased incidence of nephrotoxicity. Antimicrob Agents Chemother. 2008;52(4):1330-6.

5. Coca SG, Yusuf B, Shlipak MG, Garg AX, Parikh CR. Long-term risk of mortality and other adverse outcomes after acute kidney injury: a systematic review and meta-analysis. Am J Kidney Dis. 2009;53(6):961-73.

6. Pritchard L, Baker C, Leggett J, Sehdev P, Brown A, Bayley KB. Increasing vancomycin serum trough concentrations and incidence of nephrotoxicity. Am J Med. 2010;123(12):1143-9.

7. Minejima E, Choi J, Beringer P, Lou M, Tse E, Wong-Beringer A. Applying new diagnostic criteria for acute kidney injury to facilitate early identification of nephrotoxicity in vancomycin-treated patients. Antimicrob Agents Chemother. 2011;55(7):3278-83.

8. Lodise TP, Patel N, Lomaestro BM, Rodvold KA, Drusano GL. Relationship between initial vancomycin concentration-time profile and nephrotoxicity among hospitalized patients. Clin Infect Dis. 2009;49(4):507-14.

9. Jeffres MN, Isakow W, Doherty JA, Micek ST, Kollef MH. A retrospective analysis of possible renal toxicity associated with vancomycin in patients with health care-associated methicillin-resistant Staphylococcus aureus pneumonia. Clin Ther. 2007;29(6):1107-15.

10. Hermsen ED, Hanson M, Sankaranarayanan J, Stoner JA, Florescu MC, Rupp ME. Clinical outcomes and nephrotoxicity associated with vancomycin trough concentrations during treatment of deep-seated infections. Expert Opin Drug Saf. 2010;9(1):9-14.

11. Hidayat LK, Hsu DI, Quist R, Shriner KA, Wong-Beringer A. High-dose vancomycin therapy for methicillin-resistant Staphylococcus aureus infections: efficacy and toxicity. Arch Intern Med. 2006;166(19):2138-44.
12. Horey A, Mergenhagen KA, Mattappallil A. The relationship of nephrotoxicity to vancomycin trough serum concentrations in a veteran's population: a retrospective analysis. Ann Pharmacother. 2012;46(11): 1477-83.

13. Bosso JA, Nappi J, Rudisill C, Wellein M, Bookstaver PB, Swindler J, et al. Relationship between vancomycin trough concentrations and nephrotoxicity: a prospective multicenter trial. Antimicrob Agents Chemother. 2011;55(12):5475-9.

14. Ackerman BH, Guilday RE, Reigart CL, Patton ML, Haith LR. Evaluation of the relationship between elevated vancomycin trough concentrations and increased efficacy and/or toxicity. J Burn Care Res. 2013;34(1):e1-9.

15. McKamy S, Hernandez E, Jahng M, Moriwaki T, Deveikis A, Le J. Incidence and risk factors influencing the development of vancomycin nephrotoxicity in children. J Pediatr. 2011;158(3):422-6.

16. Ingram PR, Lye DC, Tambyah PA, Goh WP, Tam VH, Fisher DA. Risk factors for nephrotoxicity associated with continuous vancomycin infusion in outpatient parenteral antibiotic therapy. J Antimicrob Chemother. 2008; 62(1):168-71.

17. Bellomo R, Ronco C, Kellum JA, Mehta RL, Palevsky P; Acute Dialysis Quality Initiative workgroup. Acute renal failure-definition, outcome measures, animal models, fluid therapy and information technology needs: the Second International Consensus Conference of the Acute Dialysis Quality Initiative (ADQI) Group. Crit Care. 2004;8(4):R204-12.

Claire Contreiras, BSC(Pharm), ACPR, is a Clinical Pharmacist with Providence Healthcare, Vancouver, British Columbia.

Michael Legal, BSC(Pharm), ACPR, PharmD, is a Clinical Specialist, Internal Medicine, St Paul's Hospital, and Clinical Associate Professor, Faculty of Pharmaceutical Sciences, The University of British Columbia, Vancouver, British Columbia.

Tim T Y Lau, BSC(Pharm), ACPR, PharmD, FCSHP, is a Pharmacotherapeutic Specialist, Antimicrobial Stewardship and Infectious Diseases, Vancouver General Hospital; Clinical Professor, Faculty of Pharmaceutical Sciences, The University of British Columbia; and Associate Member, Division of Infectious Diseases, Department of Medicine, Faculty of Medicine, The University of British Columbia, Vancouver, British Columbia.

Rosanne Thalakada, BSC, BSC(Pharm), ACPR, PharmD, is a Pharmacy Consultant for the British Columbia Centre for Excellence in HIVIAIDS, Vancouver, British Columbia.

Stephen Shalansky, BSC(Pharm), ACPR, PharmD, FCSHP, is Clinical Coordinator, Providence Healthcare, Lower Mainland Pharmacy Services, and Clinical Professor, Faculty of Pharmaceutical Sciences, The University of British Columbia, Vancouver, British Columbia.

Mary H H Ensom, BS(Pharm), PharmD, FASHP, FCCP, FCSHP, FCAHS, is Professor, Faculty of Pharmaceutical Sciences, and Distinguished University Scholar, The University of British Columbia; and Clinical Pharmacy Specialist, Children's and Women's Health Centre of British Columbia, Vancouver, British Columbia. She is also the Editor of CJHP.

Competing interests: None declared.

\section{Address correspondence to:}

Dr Michael Legal

Pharmacy

St Paul's Hospital, Providence Health Care

1081 Burrard Street

Vancouver BC V6Z 1 Y6

e-mail: mlegal@providencehealth.bc.ca 